\section{Citations: in defence of Brazilian journals}

As editors of the Brazilian journal Reports in Public Health and signatories to the San Francisco Declaration on Research Assessment, we wish to point out that there are only four Brazilian journals among the total of 66 banned from Thomson Reuters' Journal Citation Reports (see go.nature. com/ufgbrn and Nature 500, 510-511; 2013).

According to Brazil's openaccess portal SciELO, there are more than 300 high-quality Brazilian scientific journals; these are also indexed in the main global bibliographical databases in their respective areas. They each contribute to the development of science worldwide.

This context should have been emphasized in your report, to avoid tainting the reputation of these many respected Brazilian journals by implication.

Marilia Sá Carvalho, Claudia Travassos, Claudia Medina Coeli Reports in Public Health, Rio de Janeiro, Brazil. cadernos@ensp.fiocruz.br

\section{Citations: ethical ways to grow impact}

As editors of a journal with one of the highest impact factors in Brazil, Natureza \& Conservação (the Brazilian Journal of Nature Conservation), we suggest that there are more imaginative, ethical and effective ways to increase these ratings than the cross-citation methods used by a cluster of discredited Brazilian journals (see Nature 500, 510-511; 2013).

In the past three years, our journal's impact factor has risen from 0.27 to 1.47 . This is a result of inviting submissions from respected scientists worldwide to improve our visibility. We also recruit editors who have served on reputable international journals to guarantee the quality of accepted papers.

Brazilian science is steadily improving in quality and quantity, thanks in part to strong support from two national funding agencies, the National Council for Scientific and Technological Development and the Coordination for the Improvement of Higher Education Personnel (R. D. Loyola et al. Trends Ecol. Evol. 27, 585; 2012).

These agencies have set up committees of researchers from different fields to determine how impact factors can be used effectively to evaluate graduate programmes and to rank journals. In the process, they have standardized mean impact factors to take into account impact-factor variations between subdisciplines, thereby rendering comparisons between journals more meaningful.

Brazilian journals are ripe for development - all it takes is a rational approach to optimize their impact.

Rafael Dias Loyola, José Alexandre Felizola Diniz Filho Universidade Federal de Goiás, Goiânia, Goiás, Brazil. loyola@ufg.br

\section{Citations: overcome the language barrier}

The 'citation stacking' practised by four Brazilian research journals (Nature 500, 510-511; 2013) may be a misguided attempt to compensate for the recognition problems faced by journals that do not publish in English. It is in the interest of international science for researchers and funding agencies, as well as journals, to overcome such linguistic barriers.

Impact factors depend on the size of citation pools for different languages. This favours Chinese journals published in both Chinese and English, for example, but not Brazilian journals that use Portuguese.

Transparent attempts to counteract this undue influence of language are under way. English-speaking scientists bidding for Chinese research grants, for example, enlist help from Chinese colleagues, with notable success. European nations such as Iceland and the Czech Republic require international and multilingual peer review of their research papers and grant applications - an approach that could also work for Brazilian research journals.

Ralf Buckley, Fernanda de Vasconcellos Pegas Griffith University, Gold Coast, Queensland, Australia. r.buckley@griffith.edu.au Zhong Lin-sheng Chinese Academy of Sciences, Beijing, China.

\section{Food crisis spurs aid for poverty}

Spikes in food prices in the past few years have heightened public awareness of global hunger and poverty, and have vastly increased funding for policies on agricultural development and food security. In short, we believe that the poor paradoxically stand to benefit from current high and volatile global food prices.

Mass media attention drives policy agendas (J. F. M. Swinnen and N. Francken World Econ. 29, 637-654; 2006). The jump in food prices in 2008 attracted news coverage of hunger and farmers' problems in developing countries; such coverage has since kept pace with the volatile spiking in food prices.

This has resulted in more development aid from international organizations for agriculture and hunger prevention, reversing a long downward trend (U. Lele Science 327, 1554; 2010). The private sector is also investing more in agriculture in developing countries.
We should approach today's food crisis as a valuable opportunity to combat global poverty and hunger.

Mara P. Squicciarini, Andrea Guariso, Johan Swinnen LICOS Centre for Institutions and Economic Performance, KU Leuven, Belgium. mara.squicciarini@kuleuven.be

\section{Once a scientist, always a scientist}

Many scientists, particularly chemists, have careers away from a lab bench or professorial chair - but they are still scientists (Nature 500, 369; 2013). As a mentor on careers for chemistry graduates (see go.nature.com/ ajx23f), I consider myself a chemist for life.

Our training and experience mean that we are equipped to deal with the scientific issues that frequently crop up in alternative careers. This is true for scientists who have become teachers, information specialists, patent experts and practitioners, writers and consultants, to name but a few such alternatives. We continue to understand scientific terminology, to be adept at problem-solving and to think critically about scientific matters.

This could be one reason why the American Chemical Society in Washington DC recommends alternative careers in addition to more traditional paths (see go.nature.com/vs75vj).

Robert E. Buntrock Buntrock Associates, Orono, Maine, USA. buntrock16@roadrunner.com

CONTRIBUTIONS

Correspondence may be submitted to correspondence@nature. com after consulting the author guidelines at http:// go.nature.com/cmchno. Alternatively, readers may comment online: www. nature.com/nature. 